\title{
Article \\ Bridge Damping Extraction Method from Vehicle-Bridge Interaction System Using Double-Beam Model
}

\author{
Fengzong Gong ${ }^{1}$, Fei Han ${ }^{2}$, Yingjie Wang ${ }^{3}$ and Ye Xia $1,4, * \mathbb{D}$ \\ 1 Department of Bridge Engineering, Tongji University, Shanghai 200092, China; 1932479@tongji.edu.cn \\ 2 School of Mechanics, Civil Engineering and Architecture, Northwestern Polytechnical University, \\ Xi'an 710129, China; hanfei@nwpu.edu.cn \\ 3 School of Civil Engineering, Beijing Jiaotong University, Beijing 100044, China; ceyjwang@bjtu.edu.cn \\ 4 Shanghai Qizhi Institute, Shanghai 200003, China \\ * Correspondence: yxia@tongji.edu.cn
}

Citation: Gong, F.; Han, F.; Wang, Y.; Xia, Y. Bridge Damping Extraction Method from Vehicle-Bridge Interaction System Using Double-Beam Model. Appl. Sci. 2021, 11, 10304. https://doi.org/10.3390/ app112110304

Academic Editor: Mohammad Noori

Received: 5 October 2021

Accepted: 28 October 2021

Published: 2 November 2021

Publisher's Note: MDPI stays neutral with regard to jurisdictional claims in published maps and institutional affiliations.

Copyright: (c) 2021 by the authors. Licensee MDPI, Basel, Switzerland. This article is an open access article distributed under the terms and conditions of the Creative Commons Attribution (CC BY) license (https:// creativecommons.org/licenses/by/ $4.0 /)$.
Abstract: When vehicles interact with a bridge, a vehicle-bridge interaction (VBI) system is created. The frequency and modal shape of VBI systems have been widely studied, but the damping of VBI systems has not been adequately investigated. In recent years, several incidents of abnormal bridge vibration due to changes in bridge damping have occurred and aroused widespread concern in society. Damping is an important evaluation index of structural dynamic performance. Knowing the damping ratio of a VBI system is useful for analyzing the damping changes while a bridge is in service. This paper presents a method to extract bridge damping values from a VBI system, which can serve as a guide for bridge damping evaluation. First, a double-beam theoretical model was used to simplify the VBI system for cases involving uniform traffic flow. The damping ratio equation for the simplified VBI system was obtained using the extended dynamic stiffness method (EDSM). A double-beam finite element model and a VBI finite element model were established. The damping ratios of the two models were separately calculated and then compared with the simplified VBI model results. The results verified the accuracy of the simplified method. This paper then explains that bridge damping values can be extracted by estimating the equivalent traffic flow parameters and using the damping formula for the simplified VBI system. The bridge damping ratios extracted using this method in an engineering case ranged from $0.75 \%$ to $0.78 \%$, which is smaller than the range that was directly identified using monitoring data (0.83-1.19\%). The results show that the method can effectively extract bridge damping ratios and improve damping ratio identification.

Keywords: vehicle-bridge interaction; double-beam system; extended dynamic stiffness method (EDSM); bridge damping

\section{Introduction}

Vehicle-bridge interaction (VBI) has been extensively studied in the field of structural health monitoring (SHM) [1]. Numerous studies have shown that the dynamic characteristics of VBI systems differ from those of bridges, and this difference often cannot be ignored [2-5]. Traffic loads, as an important load in bridge operation, cause such differences in dynamic characteristics that have important impacts on the condition assessment of bridges.

The influence of the vehicle-bridge coupling effect on bridge frequency has been extensively studied. Yang [5] used a spring mass model to simulate a vehicle, in which the closed-form solutions of the VBI system for a vehicle traveling over a bridge were calculated when the first-order modal of the bridge was considered without damping. Li [6] proposed a method to extract the frequencies of a VBI system using the synchroextracting transform technique. Numerical studies have demonstrated the effectiveness of the method, and the frequency identification results are in general agreement with the theoretical solution proposed by Yang [5]. Matsuoka [7] used a Bayesian time-frequency analysis method to 
identify the change of frequency when a train crosses a bridge. This method was also shown to be good at extracting the time-varying frequency characteristics of a VBI system. Cantero [8] conducted an experiment to measure the evolution of the modal properties of a bridge as a vehicle drives across it. Vehicle and modal frequency were analyzed at different bridge locations using a simplified vehicle model with a spring mass. The study found that the spring mass vehicle model was able to accurately explain the phenomena in the experiment.

A vehicle suspension system is similar to an additional damper that absorbs and reduces bridge vibrations [7]. This process causes the damping of a VBI system to be greater than the damping of the bridge. Therefore, the vehicle-bridge coupling effect has an impact on the damping identification results of a bridge. In bridge health monitoring, the damping identified by monitoring data often has a large dispersion problem $[9,10]$. The presence of traffic on a bridge usually causes the damping identified using bridge monitoring data to be that of the VBI system, which is an important reason for the large dispersion of damping identification results. However, in the field of SHM, a large amount of research has focused on developing damping identification algorithms to improve the accuracy of results, and few studies have analyzed the dispersion of damping identification results from the perspective of vehicle-bridge coupling effects. Sunjoong [11] proposed using a dynamic displacement reconstruction algorithm to suppress the higher-order modal components and then using the Natural Excitation Technique combined with the Eigensystem Realization Algorithm (NExT-ERA) to identify the damping ratio of a reconstructed displacement. Wang [12] used the random decrement technique (RDT) and wavelet transformation (WT) to identify the damping ratio of Sutong Bridge during a typhoon. Sunjoong [13] proposed using an amplitude-modulation function to pre-process the measured data and then used the operational modal analysis (OMA) method to identify the damping ratio. Hwang [9] used 2.5 years of bridge monitoring data to analyze the variation pattern of a damping ratio with a displacement reconstruction algorithm, but the identification results still showed relatively large fluctuations. Therefore, it is important to study the effect of the vehicle-bridge coupling effect on bridge damping identification and extract the bridge damping ratio from a VBI system to improve the accuracy of bridge damping ratio identification results.

In recent years, there have been reports of abnormal vibrations on two bridges in China that have attracted widespread attention in society. One of the bridges was the Humen Bridge in Guangdong. A change in the dynamic characteristics of the bridge is suspected to be one of the causes of this incident. This bridge experienced vortex-induced vibrations after a long period of traffic closure. In order to study the effect of traffic on the dynamic characteristics of bridges, Dan [14] proposed that the double-beam system can be used to analyze the damping variation law of VBI systems. However, the accuracy of using the double-beam system to simplify a VBI system was not explored in more depth and the estimation method of the traffic flow parameters in the model was not given, which makes it difficult to apply the simplified model to practical engineering. In this paper, this simplified model was investigated for the damping problem of VBI systems under uniform traffic flow conditions. It was verified that the simplified VBI model has dynamic characteristics consistent with the VBI system. An estimation method of equivalent traffic flow parameters was proposed to achieve the evaluation of bridge damping from the dynamic characteristics of VBI systems. Finally, the damping ratio was extracted for a real bridge using the proposed method.

This paper is organized as follows: first, a method to simplify a VBI system using the double-beam system is provided. Then, the damping ratio calculation method of the simplified model of a VBI system is derived. The accuracy of using the simplified model to calculate the damping ratio of a VBI system is verified by a numerical simulation, and the effect of vehicle damping on the damping ratio of a VBI system is analyzed. Then, the evaluation method of equivalent traffic flow parameters is proposed, and the evaluation 
process of the bridge damping ratio considering the vehicle-bridge coupling effect is given. Finally, the method is applied to the damping evaluation of a real bridge.

\section{Formulation of the Analytical Theory}

This section introduces a method to simplify a VBI system using a double-beam system, offers the governing differential equations for the simplified model, and uses the extended dynamic stiffness method (EDSM) to derive the damping ratio formula for the simplified model.

\subsection{Simplification of VBI System}

In the VBI problem, the vehicle body and bridge are generally considered to be connected by a vehicle suspension system. The vehicle model is simplified to a spring mass model, as shown in Figure 1, such as the 1/2 car or 1/4 car model [15-19]. In this paper, the 1/4 car model, which ignores the suspension mass in (c), was used. Since the purpose of this study did not require an accurate VBI system response calculation, model (c) was convenient and effective for explaining the effect of axle coupling on the damping of a VBI system.

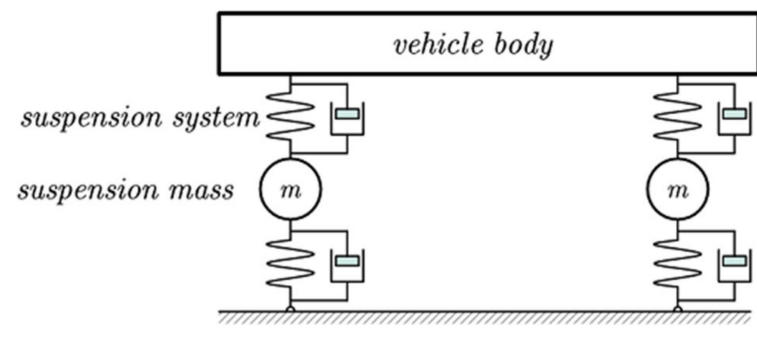

(a)

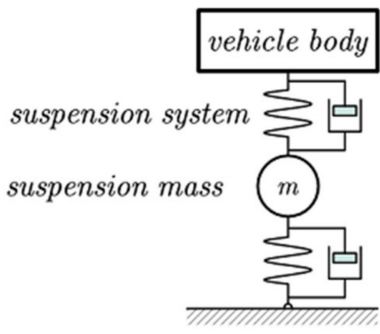

(b)

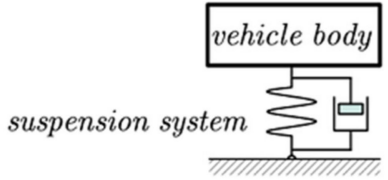

(c)

Figure 1. Simplified plane models of the vehicle: (a) $1 / 2$ car model; (b) $1 / 4$ car model; (c) $1 / 4$ car model without suspension mass.

Only uniform traffic flow acting on the bridge was considered in this study. Uniform traffic flow refers to traffic flow in which each vehicle has the same dynamic parameters (e.g., the distance between vehicles is the same and the traffic flows at the same speed). In this case, the vehicle suspension system is modeled as uniformly distributed springs and dampers, and the vehicle body traveling across the bridge is modeled as a Euler beam with zero flexural stiffness and a zero damping coefficient, effectively reducing a VBI system into a double-beam system, as shown in Figure 2. The upper girder boundary conditions are free-free, while the lower girder boundary conditions depend on the bridge. The upper beam mass, connection layer stiffness, and double-beam system damping coefficient can be replaced by the equivalent traffic flow parameters, which are defined as follows:

$$
m^{\prime}=n m_{v} / L, k^{\prime}=n k_{v} / L, c^{\prime}=n c_{v} / L
$$

where $m_{v}$ is the average mass of vehicles on the bridge; $k_{v}$ and $c_{v}$ are the average vehicle stiffness and the average vehicle damping factor, respectively; $n$ is the number of vehicles on the bridge; and $L$ is the bridge length. 


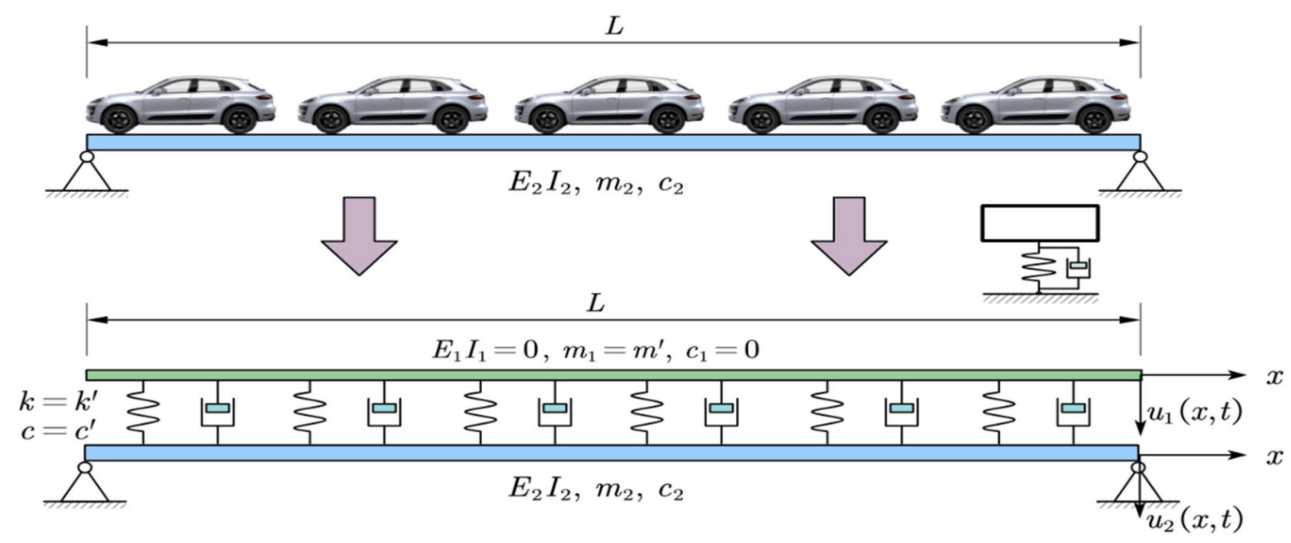

Figure 2. Simplified schematic of a VBI system.

\subsection{Governing Differential Equations of Double-Beam System}

The elasticity modulus of the two beams of the double-beam system are $E_{1}$ and $E_{2}$, the cross-sectional moments of inertia are $I_{1}$ and $I_{2}$, the masses per unit length are $m_{1}$ and $m_{2}$, and the damping coefficients are $c_{1}$ and $c_{2}$. The stiffness and damping coefficients of the connection layer are $k$ and $c$, respectively. The governing differential equations (GDE) of this double-beam system can be expressed as:

$$
\left\{\begin{array}{l}
E_{1} I_{1} \frac{\partial^{4} u_{1}}{\partial x^{4}}+m_{1} \frac{\partial^{2} u_{1}}{\partial t^{2}}+c_{1} \frac{u_{1}}{\partial t}+c \frac{\partial\left(u_{1}-u_{2}\right)}{\partial t}+k\left(u_{1}-u_{2}\right)=0 \\
E_{2} I_{2} \frac{\partial^{4} u_{2}}{\partial x^{4}}+m_{2} \frac{\partial^{2} u_{2}}{\partial t^{2}}+c_{2} \frac{u_{2}}{\partial t}+c \frac{\partial\left(u_{2}-u_{1}\right)}{\partial t}+k\left(u_{2}-u_{1}\right)=0
\end{array}\right.
$$

where $u_{1}$ and $u_{2}$ are the displacement values of the two beams.

The variable separation can be performed in the Laplace domain as follows:

$$
u_{1}(x, t)=\varphi_{1}(x) e^{\lambda t}, u_{2}(x, t)=\varphi_{2}(x) e^{\lambda t}
$$

where $\varphi_{1}(x)$ and $\varphi_{2}(x)$ represent the mode shape functions of the two beams and can be analytically expressed as:

$$
\varphi_{1}(x)=\bar{A} e^{\kappa x}, \varphi_{2}(x)=\bar{B} e^{\kappa x}
$$

where $\bar{A}$ and $\bar{B}$ are undetermined coefficients related to the boundary condition. By substituting Equations (3) and (4) into the double-beam system GDE Equation (2), one can obtain the following:

$$
\left\{\begin{array}{l}
\bar{A}\left(E_{1} I_{1} \kappa^{4}+k+\lambda\left(c_{1}+c\right)+m_{1} \lambda^{2}\right)-\bar{B}(k+c \lambda)=0 \\
\bar{B}\left(E_{2} I_{2} \kappa^{4}+k+\lambda\left(c_{2}+c\right)+m_{2} \lambda^{2}\right)-\bar{A}(k+c \lambda)=0
\end{array}\right.
$$

The matrix form of Equation (5) is:

$$
\left(\begin{array}{cc}
E_{1} I_{1} \kappa^{4}+k+\lambda\left(c_{1}+c\right)+m_{1} \lambda^{2} & -k-c \lambda \\
-k-c \lambda & E_{2} I_{2} \kappa^{4}+k+\lambda\left(c_{2}+c\right)+m_{2} \lambda^{2}
\end{array}\right)\left(\begin{array}{c}
\bar{A} \\
\bar{B}
\end{array}\right)=\left(\begin{array}{l}
0 \\
0
\end{array}\right)
$$

For this equation to have a non-trivial solution, the value of the coefficient matrix determinant of $\bar{A}$ and $\bar{B}$ is zero. As a result, a characteristic equation for an 8th order polynomial with respect to $\mathcal{K}$ can be obtained as follows:

$$
\eta_{3} \kappa^{8}+\eta_{2} \kappa^{4}+\eta_{1}=0
$$

where

$\eta_{3}=E_{1} I_{1} E_{2} I_{2}$ 


$$
\begin{aligned}
& \eta_{2}=E_{1} I_{1}\left(k+\lambda\left(c_{1}+c\right)+m_{2} \lambda^{2}\right)+E_{2} I_{2}\left(k+\lambda\left(c_{2}+c\right)+m_{1} \lambda^{2}\right) \\
& \eta_{1}=\left(k+\lambda\left(c_{1}+c\right)+m_{1} \lambda^{2}\right)\left(k+\lambda\left(c_{2}+c\right)+m_{2} \lambda^{2}\right)-(k+c \lambda)^{2}
\end{aligned}
$$

The solution of the characteristic equation is $\pm \kappa_{1}, \pm \kappa_{2}, \pm \kappa_{3}, \pm \kappa_{4}$, and the general solution of Equation (3) can be expressed as:

$$
\begin{gathered}
\varphi_{1}(x)=\bar{A}_{1} e^{\kappa_{1} x}+\bar{A}_{2} e^{-\kappa_{1} x}+\bar{A}_{3} e^{\kappa_{2} x}+\bar{A}_{4} e^{-\kappa_{2} x}+\bar{A}_{5} e^{\kappa_{3} x}+\bar{A}_{6} e^{-\kappa_{3} x}+\bar{A}_{7} e^{\kappa_{4} x}+\bar{A}_{8} e^{-\kappa_{4} x} \\
=\sum_{j=1}^{8}\left(\bar{A}_{2 j-1} e^{\kappa_{j} x}+\bar{A}_{2 j} e^{-\kappa_{j} x}\right) \\
\varphi_{2}(x)=\bar{B}_{1} e^{\kappa_{1} x}+\bar{B}_{2} e^{-\kappa_{1} x}+\bar{B}_{3} e^{\kappa_{2} x}+\bar{B}_{4} e^{-\kappa_{2} x}+\bar{B}_{5} e^{\kappa_{3} x}+\bar{B}_{6} e^{-\kappa_{3} x}+\bar{B}_{7} e^{\kappa_{4} x}+\bar{B}_{8} e^{-\kappa_{4} x} \\
=\sum_{j=1}^{8}\left(\bar{B}_{2 j-1} e^{\kappa_{j} x}+\bar{B}_{2 j} e^{-\kappa_{j} x}\right)
\end{gathered}
$$

The relationship between $\bar{A}$ and $\bar{B}$ is given by:

$$
\bar{B}_{2 j-1}=t_{j} \bar{A}_{2 j-1}, \bar{B}_{2 j}=t_{j} \bar{A}_{2 j}
$$

where $t_{j}=\frac{E_{1} I_{1} \kappa_{j}^{4}+k+\lambda\left(c_{1}+c\right)+m_{1} \lambda^{2}}{k+c \lambda}$.

\subsection{Extended Dynamic Stiffness Method}

Han $[20,21]$ proposed a method for solving damped double-beam systems using the extended dynamic stiffness method (EDSM). According to the uniformity of the dynamic stiffness matrix between the damped and undamped system, the dynamic stiffness matrix of the damped system is denoted as $K(\kappa)$ and the dynamic stiffness matrix of the undamped system is denoted as $\boldsymbol{K}\left(\kappa_{0}\right)$; for the same order mode there is:

$$
\kappa_{0}=\kappa,|K(\kappa)|=\left|K\left(\kappa_{0}\right)\right|=\mathbf{0}
$$

Substituting $c=c_{1}=c_{2}=0$ into Equation (5) results in:

$$
\left\{\begin{array}{l}
\bar{A}\left(E_{1} I_{1} \kappa_{0}^{4}+k+m_{1} \lambda_{0}^{2}\right)-\bar{B} k=0 \\
\bar{B}\left(E_{2} I_{2} \kappa_{0}^{4}+k+m_{2} \lambda_{0}^{2}\right)-\bar{A} k=0
\end{array}\right.
$$

According to Equation (11), Equation (13) can be obtained:

$$
\lambda^{2}+\frac{2 c(\bar{A}-\bar{B})+\left(\bar{A} c_{1}-\bar{B} c_{2}\right)}{\left(\bar{A} m_{1}-\bar{B} m_{2}\right) \lambda_{0}} \lambda \lambda_{0}+\lambda_{0}^{2}=0
$$

where $\lambda_{0}=\omega_{0} i, \omega_{0}$ is the modal frequency corresponding to the undamped double beam system. The damping ratio of the double beam system is:

$$
\xi=\frac{2 c(\bar{A}-\bar{B})+\left(\bar{A} c_{1}-\bar{B} c_{2}\right)}{2\left(\bar{A} m_{1}-\bar{B} m_{2}\right) \omega_{0}}
$$

The solution of Equation (13) is:

$$
\lambda=\xi \lambda_{0} i \pm \sqrt{1-\xi^{2}} \lambda_{0}=-\xi \omega_{0} \pm \sqrt{1-\xi^{2}} \omega_{0} i
$$

where the imaginary part of the solution is the self-oscillation frequency of the damped double beam system.

$$
\omega=\sqrt{1-\xi^{2}} \omega_{0}
$$

The Wittrick-Williams (W-W) algorithm [22] is a well-known method for calculating frequency using the dynamic stiffness method. Instead of directly solving the frequency 
equation, the $\mathrm{W}-\mathrm{W}$ algorithm first determines the upper and lower bounds of any order frequency and then finds the exact frequency via the dichotomy method or Newton's method. Han $[23,24]$ proposed an improved $\mathrm{W}-\mathrm{W}$ algorithm to conveniently solve the frequency of an undamped double-beam system. The authors of this study used the improved $\mathrm{W}-\mathrm{W}$ algorithm. The mode shape is calculated using the guided Newton method, and the detailed solution steps of the method can be found in $[25,26]$.

By substituting the damping coefficient $c_{1}=0$ of the upper beam of the double-beam system into Equation (14), the damping ratio of the VBI system is obtained as:

$$
\xi=\frac{2 c(\bar{A}-\bar{B})-\bar{B} c_{2}}{2\left(\bar{A} m_{1}-\bar{B} m_{2}\right) \omega_{0}}
$$

As seen in Equation (17), the damping ratio of the vehicle-bridge coupled system is related to vehicle and bridge amplitudes, vehicle damping coefficient, bridge damping coefficient, and vehicle and bridge masses, where $\omega_{0}$ is the frequency corresponding to the undamped VBI system, not the frequency of the bridge.

\section{Verification of the Simplified VBI Model}

To illustrate the accuracy of the simplified model in the damping calculation of a VBI system, two models are established in this section: the double-beam finite element model (FEM) and the VBI finite element model, as shown in Figures 3 and 4. The damping ratios of the models were separately calculated using the dynamic response of the two models, and the damping ratio calculation results were compared with the damping ratio calculation equation of the double-beam system obtained in Section 2.1. The results showed that the theoretical model of the double-beam system could accurately simulate the damping of a VBI system. Finally, the variation of VBI system damping corresponding to the bridge was analyzed under different traffic conditions using the simplified model.

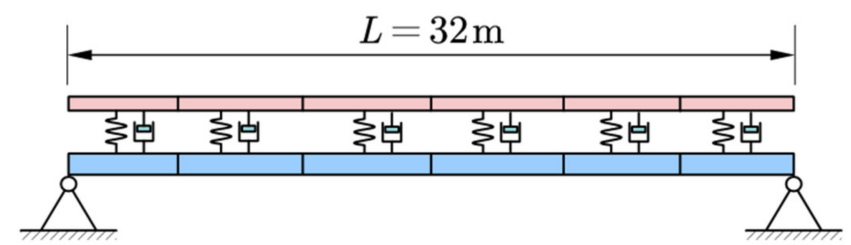

Figure 3. The double-beam finite element model.

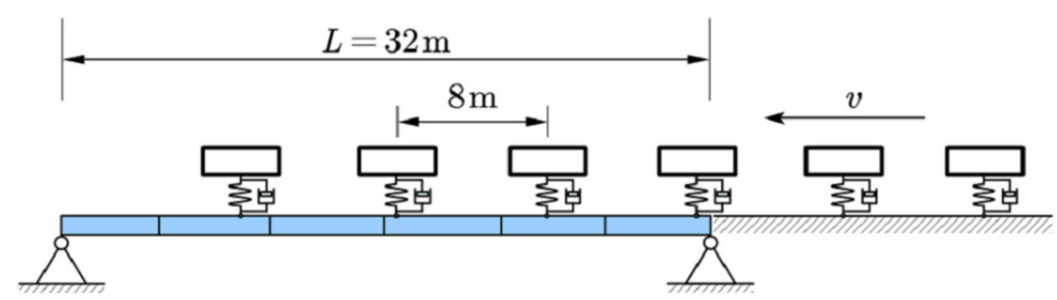

Figure 4. The VBI finite element model.

\subsection{Description of the Bridge Model and the Vehicle Model}

The bridge had the following parameters: bridge length $L=32 \mathrm{~m}$, flexure stiffness $E_{2} I_{2}=11.04 \times 10^{11} \mathrm{Nm}^{2}$, and bridge mass per unit length $m_{2}=28,600 \mathrm{~kg} / \mathrm{m}$. The first order frequency of the bridge was $9.5306 \mathrm{~Hz}$. The damping coefficient of the bridge was set to $c_{2}=0 \mathrm{Ns} / \mathrm{m}$ to visualize the vehicle damping effect on the VBI system.

The $1 / 4$ vehicle model was used, and the vehicle parameters were as follows: vehicle body mass $m_{v}=20 \mathrm{t}$ and suspension system stiffness $k_{v}=10.14 \times 10^{6} \mathrm{~N} / \mathrm{m}$. The undamped self-oscillation frequency of the vehicle was $3.82 \mathrm{~Hz}$. The suspension system damping factor was $c_{v}=7.64 \times 10^{4} \sim 7.64 \times 10^{5} \mathrm{Ns} / \mathrm{m}$. The uniform traffic flow consisted of four vehicles spaced $8 \mathrm{~m}$ apart with the same parameters and traveling at the 
same speed. The case study then considered three conditions, as follows: Case 1: uniform traffic flow with a speed of $20 \mathrm{~km} / \mathrm{h}$; Case 2: uniform traffic flow with a speed of $40 \mathrm{~km} / \mathrm{h}$; and Case 3: random traffic flow with an average speed of $40 \mathrm{~km} / \mathrm{h}$. The vehicle parameters and speed of the random traffic in Case 3 were generated using a Gaussian distribution, where the mean value of each distribution was the same as that of the uniform traffic, with a standard deviation of 0.2 times the mean value.

The bridge and vehicle parameters described above were simplified to obtain the parameters of the double-beam finite element model using the method outlined in Section 2.1. The impact load was applied to the double-beam finite element model, and the acceleration of the structure was calculated using the Newmark method with a time step of $0.001 \mathrm{~s}$.

The acceleration of the bridge could be obtained by calculating the response of the VBI system as traffic passes over a bridge. The differential equation of a VBI system can be expressed as:

$$
\left\{\begin{array}{l}
\mathbf{M}_{v} \ddot{\mathbf{Z}}_{v}+\mathbf{C}_{v} \dot{\mathbf{Z}}_{v}+\mathbf{K}_{v} \mathbf{Z}_{v}=\mathbf{F}_{v} \\
\mathbf{M}_{b} \ddot{\mathbf{Z}}_{b}+\mathbf{C}_{b} \dot{\mathbf{Z}}_{b}+\mathbf{K}_{b} \mathbf{Z}_{b}=\mathbf{F}_{b}
\end{array}\right.
$$

where the mass, damping, stiffness, and load matrices of the vehicle are $\mathbf{M}_{v}, \mathbf{C}_{v}, \mathbf{K}_{v}$, and $\mathbf{F}_{v}$, respectively. The mass, damping, stiffness, and load matrices of the bridge are $\mathbf{M}_{b}, \mathbf{C}_{b}$, $\mathbf{K}_{b}$, and $\mathbf{F}_{b}$, respectively. The axle interaction relationship is constructed through the load vectors, $\mathbf{F}_{v}$ and $\mathbf{F}_{b}$, of the two systems.

$$
\begin{gathered}
\mathbf{F}_{v}=\mathbf{K}_{v} \mathbf{S}+\mathbf{C}_{v} \dot{\mathbf{S}} \\
\mathbf{F}_{b}=\mathbf{K}_{v}\left(\mathbf{Z}_{v}-\mathbf{S}\right)+\mathbf{C}_{v}\left(\dot{\mathbf{Z}}_{v}-\dot{\mathbf{S}}\right)+\mathbf{G}_{v}
\end{gathered}
$$

where $\mathbf{S}$ is the vertical displacement at the location of the contact point between the vehicles and the bridge and $\mathbf{G}_{v}$, is the gravitational force on the vehicle.

While there have been many approaches to calculating VBI system response, this study used the inter-system iterative method (ISI) proposed by Zhang [27]. This method enables easy calculated, and its convergence is convenient to control, which is suitable for the VBI calculation problem, especially in cases involving multiple vehicles.

Figure 5 shows the decay response of the double-beam finite element model subjected to impact loading in the bridge span. The acceleration response of a bridge obtained by VBI calculations usually had multiple frequency components. To calculate the damping ratio, the acceleration response needed to be band-pass filtered so that only one frequency component was included in the acceleration response. Figure 6 shows the acceleration response of a bridge system in the bridge mid-span after band-pass filtering when the traffic passed by, the traffic presented a uniform flow, and the speed was $20 \mathrm{~km} / \mathrm{h}$. As seen in Figure 6, when there was traffic on the bridge, even if the bridge damping factor was zero, the response of the bridge still decayed similar to that shown Figure 5. When the traffic left the bridge, however, the bridge response became a free vibration without decay.

\subsection{Analysis of Results}

The damping ratio of the system was calculated for the double-beam finite element model and the VBI finite element model using the decay responses in Figures 5 and 6. In this paper, the HHT method [28] was used to calculate the damping ratio. This method could effectively reduce the identification error of a damping ratio through least square fitting. 


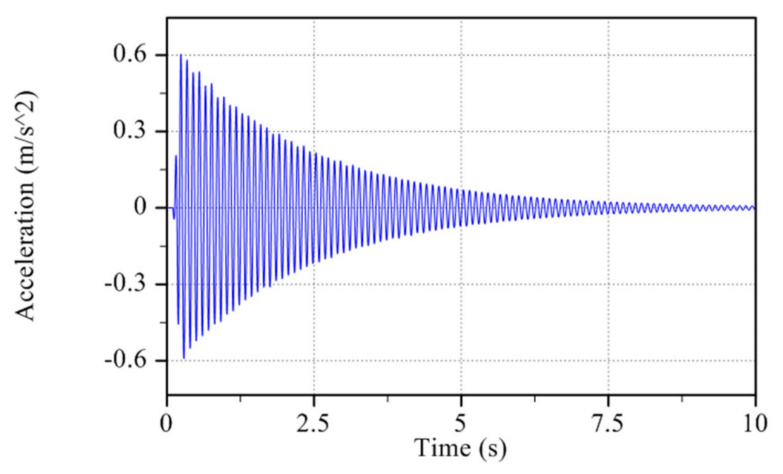

Figure 5. Mid-span acceleration of the double-beam system.

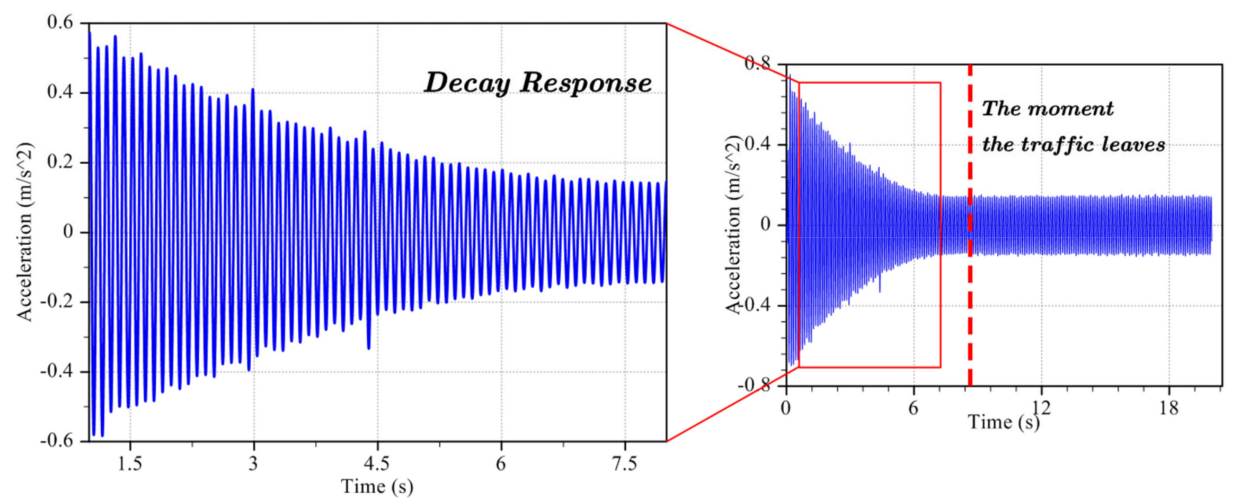

Figure 6. Bridge mid - span acceleration for VBI model (results after bandpass filtering; vehicle speed was $20 \mathrm{~km} / \mathrm{h}$ ).

For this study, the damping ratios of the two models were calculated. Then, the formula in Section 2 was used to calculate the damping ratio of the simplified model. Table 1 shows the damping ratio results obtained for each model.

Table 1. Damping ratio calculation results for each model.

\begin{tabular}{cccccc}
\hline $\begin{array}{c}\text { Vehicle Damping } \\
\text { Ratio }\end{array}$ & $\begin{array}{c}\text { Double-Beam } \\
\text { Theory }\end{array}$ & $\begin{array}{c}\text { Double-Beam } \\
\text { FEM }\end{array}$ & $\begin{array}{c}\text { VBI System FEM } \\
\text { (Case 1) }\end{array}$ & $\begin{array}{c}\text { VBI System FEM } \\
\text { (Case 2) }\end{array}$ & $\begin{array}{c}\text { VBI System FEM } \\
\text { (Case 3) }\end{array}$ \\
\hline 0.085 & 0.0046 & 0.0037 & 0.0040 & 0.0043 & 0.0036 \\
0.170 & 0.0089 & 0.0073 & 0.0076 & 0.0073 & 0.0066 \\
0.339 & 0.0155 & 0.0139 & 0.0136 & 0.0134 & 0.0137 \\
0.509 & 0.0196 & 0.0190 & 0.0185 & 0.0180 & 0.0191 \\
0.678 & 0.0216 & 0.0225 & 0.0212 & 0.0209 & 0.0223 \\
0.848 & 0.0220 & 0.0245 & 0.0228 & 0.0213 & 0.0201 \\
\hline
\end{tabular}

The damping ratio calculation results of the double-beam theory and the doublebeam FEM showed that the double-beam theory could accurately calculate the damping ratio of the system. The results Case 1 and Case 2, as well as the double-beam theory, showed that the damping ratios were close to each other, which verified the accuracy of the simplified VBI system using the double-beam system. The results of Case 1 and Case 2 also showed that the vehicle speed in the VBI model had little influence on the damping ratio of the system.

The random traffic conditions in Case 3 were set up to illustrate the robustness of the simplified method proposed in this paper. The variation pattern of the damping ratio in Case 3 was essentially the same as that in the uniform traffic condition, which indicates 
that the simplified model could still well simulate the damping ratio of the VBI system under some stochastic conditions.

Table 1 shows that the damping ratio of the vehicle increased as the damping ratio of the VBI system increased, but there was not a linear relationship between these two variables. When the vehicle damping ratio increased from 0.678 to 0.848 , the damping ratio of the VBI system changed very little. To understand the relationship between VBI system damping ratio and the vehicle damping ratio, the simplified model of the VBI system was used to calculate the damping of the VBI system under different vehicle damping ratios. The results are shown in Figure 7.

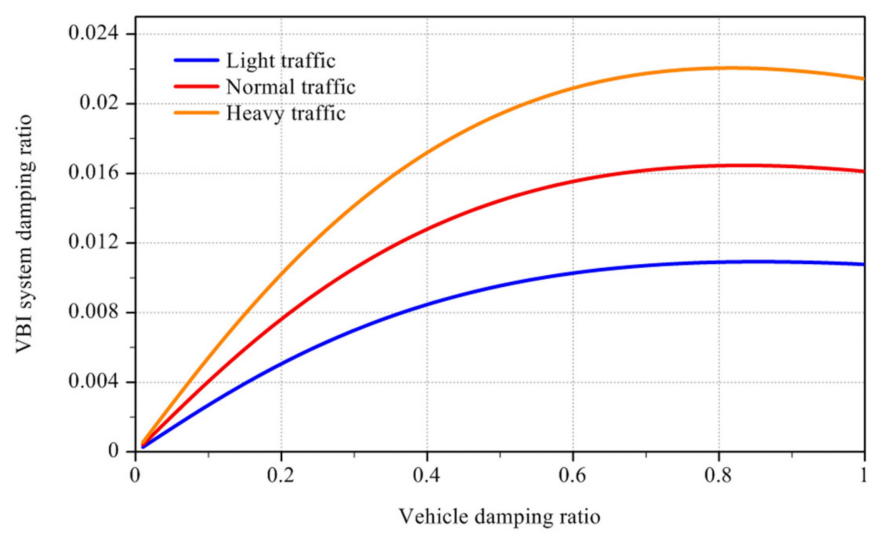

Figure 7. Damping ratio for a VBI system.

The damping ratios of the VBI system are shown in Figure 7 for three traffic conditions: light traffic $(n=1,2)$, normal traffic $(n=3)$, and heavy traffic $(n=4)$. As seen in Figure 7 , the damping ratio of the VBI system increased as the traffic volume increased. When the vehicle damping ratio was relatively small, the damping ratio of the VBI system was approximately linear with the vehicle damping ratio. After the vehicle damping ratio was greater than 0.8 , however, the damping ratio of the VBI system slightly decreased. The reason is analyzed as follows: Equation (17) shows that the damping ratio of a VBI system is related to the bridge and vehicle amplitudes. When the vehicle damping ratio is large, the relative amplitude of both the vehicle and the bridge decreases. Following additional damping energy dissipation, the vehicle damping ratio is also reduced, resulting in a reduction of the damping ratio of the VBI system.

\section{Bridge Damping Ratio Extraction Method}

The method proposed in this study can be used to extract bridge damping ratios by removing the vehicle-bridge coupling effect from the dynamic characteristics (frequency and damping ratio) of a VBI system. In bridge health monitoring, the structure is usually monitored using a bridge health monitoring system that requires the frequency $\omega$ and damping ratio $\xi$, which can be calculated using the OMA [29-31] method. Because of the presence of traffic on the bridge during the monitoring period, we obtained the dynamic parameters of the VBI system using the monitoring data rather than the dynamic parameters of the bridge. The damping ratio of the bridge structure was extracted using Equation (17) after simplifying the VBI system by calculating the equivalent vehicle flow parameters using Equation (1) with known information on the mass, stiffness, and the vehicle damping coefficient.

In general, many bridge health monitoring systems are installed with Weigh-In-Motion (WIM) systems, which can obtain information on the number and mass of vehicles. Since vehicle stiffness and damping coefficient usually remain unknown while using WIM monitoring systems, it is difficult to determine the equivalent traffic flow parameters. The authors of this study proposed a method to estimate the equivalent traffic flow parameters and then validated this estimation model using numerical simulations. 
The assumption that the average vehicle stiffness is $k_{v}$ and the average vehicle damping is $c_{v}$ remain constant over time is acceptable because traffic volumes and vehicle types in a traffic route usually have a certain statistical pattern. Under this assumption, the equivalent traffic flow parameters only vary with the known number of vehicles $n$. As a result, it is only necessary to determine the constants $k_{v}$ and $c_{v}$ to calculate the equivalent traffic flow parameters.

\subsection{Equivalent Traffic Flow Stiffness}

The estimation of the model parameters is an inverse problem compared to the frequency solution process for the simplified VBI model. The frequency $\omega$ and the damping ratio $\xi$ of a VBI system are known after solving for the undamped VBI simplified model frequencies $\omega_{0}$ using Equation (16), and then subsequent estimation can be performed in the corresponding undamped simplified VBI model.

The undamped VBI system frequency $\omega_{0}=f\left(\omega_{b}, n k_{v} / L, n m_{v} / L\right)$ is a function of bridge frequency $\omega_{b}$, the number of vehicles $n$, average vehicle stiffness $k_{v}$, and mass $m_{v}$. Here, the number of vehicles $n$ and the average vehicle mass $m_{v}$ are considered known, and the frequency of the bridge $\omega_{b}$ can be determined when $\omega_{0}$ and $k_{v}$ are given. However, the function $\omega_{0}=f\left(\omega_{b}, n k_{v} / L, n m_{v} / L\right)$ does not have an analytic formula, so only numerical algorithms (such as the optimization methods) can be used to calculate $\omega_{b}$.

Based on the above analysis, when any of the $k_{v}$, is combined with the $\omega_{0}$ obtained using the measured response, an estimated bridge frequency $\omega_{b}$ can be obtained. Therefore, in order to obtain an estimate of the bridge frequency as accurate as possible, a suitable method needs to be selected to determine $k_{v}$. Since the frequency of a bridge does not vary with the number of vehicles $n$, the absolute value of the slope of the line obtained by linear least squares of $\omega_{b}$ and $n$ can be used as the selected evaluation index, as follows:

$$
R=\left|\frac{\sum_{i=1}^{m}\left(\hat{\omega}_{b i}-\overline{\hat{\omega}}_{b}\right)\left(n_{i}-\bar{n}\right)}{\sum_{i=1}^{m}\left(n_{i}-\bar{n}\right)^{2}}\right|
$$

where $m$ is the number of samples, i.e., the number of samples of bridge frequencies and damping ratios obtained at different vehicle number $n ; \hat{\omega}_{b i}$ is the $i$-th bridge frequency sample; $\overline{\hat{\omega}}_{b}$ is the bridge frequency average; $n_{i}$ is the $i$-th vehicle number samples; and $\bar{n}$ is the average of the number of vehicle samples.

Using the parametric optimization algorithm, Equation (21) can be used as the objective function, and the value $k_{v}$ that minimizes the objective function can be selected. Commonly used methods for parameter optimization include genetic algorithms (GAs) [32,33] and particle swarm optimization (PSO) algorithms [34]. The authors of this paper used a PSO algorithm to optimize the objective function. The algorithm was not the focus of this study, and the specific details of the algorithm can be found in the related literature.

\subsection{Equivalent Traffic Flow Damping and Bridge Damping}

According to the relationship of mode shape $\bar{B}=t \bar{A}$, the damping ratio of a VBI system can be written as:

$$
\xi=\frac{2 c(1-t)-\bar{t} c_{2}}{2\left(m_{1}-t m_{2}\right) \omega_{0}}
$$

where $t$ denotes the ratio of bridge vibration to vehicle vibration amplitude. The value of $t$ can be calculated using the double-beam theory after obtaining an estimate of $k_{v}$, combining the undamped frequency $\omega_{0}$ of a VBI system and the damping ratio $\xi$. According to Equation (10), four values of $t_{i}, i=1 \sim 4$ can be calculated; for simplified VBI systems $E_{1} I_{1}=0, t_{i}$ values are the same, so it is abbreviated here as $t$. The formula for $t$ is:

$$
t=\frac{k+\lambda c+m_{1} \lambda^{2}}{k+c \lambda}
$$


Therefore, the bridge damping factor is:

$$
c_{2}=\frac{2 c(1-t)-2\left(m_{1}-t m_{2}\right) \omega_{0} \xi}{t}
$$

It is also necessary to determine the equivalent traffic damping factor $c$ in order to obtain an estimate of the bridge damping factor $c_{2}$. The equivalent traffic flow damping factor can be selected as follows. When the number of vehicles on the bridge is $n$, a series of different test values of $c_{v}$ are used to calculate the equivalent traffic flow coefficient. Then, a series of different identification values of bridge damping coefficient are obtained using Equation (24). The curve of bridge damping coefficient identification value is drawn with $c_{v}$. When the vehicle number $n$ is different, the obtained curves are also different. Because the bridge damping coefficient remains unchanged, these curves will intersect at one point. The horizontal coordinate corresponding to the intersection is the average vehicle damping coefficient $c_{v}$, and the vertical coordinate is the estimated value of the bridge damping coefficient $c_{2}$.

The process of the bridge damping ratio evaluation method proposed in this paper can be summarized as follows:

1. The frequency and damping ratio of a VBI system is identified using the OMA method based on bridge monitoring data. This process considers the number of vehicles and vehicle masses to be known in the presence of a WIM system.

2. The corresponding undamped frequency of the VBI system is calculated using Formula (16).

3. The best estimation of average vehicle stiffness is obtained by PSO, taking the absolute value of the slope of the line obtained by linear least squares between vehicle bridge system frequency and vehicle number as the objective function. Then, the equivalent vehicle flow stiffness is calculated.

4. The bridge damping coefficient curves under different vehicle numbers are solved using a series of average vehicle damping test values.

5. The horizontal coordinate of the intersection of the curves is the estimated value of the average vehicle damping, and the vertical coordinate is the estimated value of the bridge damping coefficient.

A flow chart of the proposed bridge damping evaluation method is shown in Figure 8.

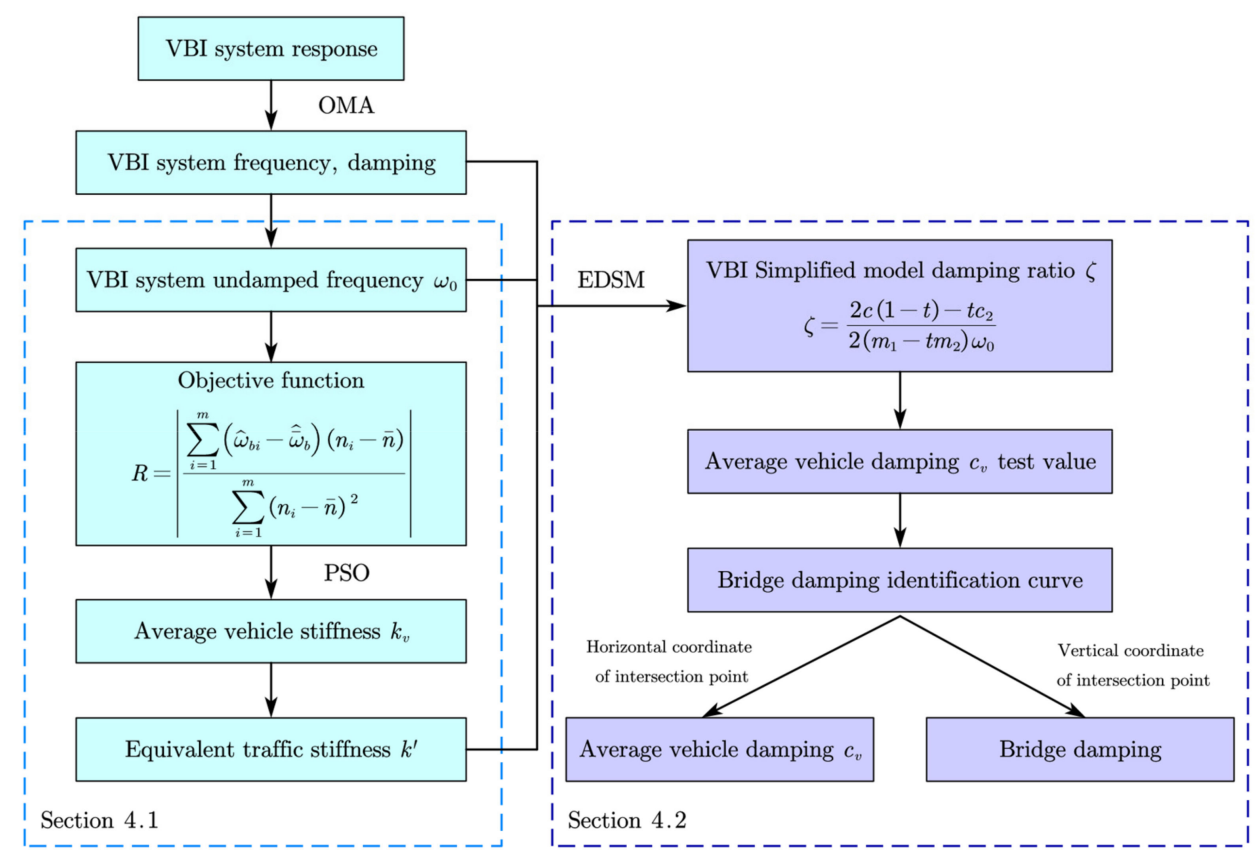

Figure 8. Bridge damping ratio evaluation flow chart. 


\subsection{Numerical Case Analysis}

This case analysis used the bridge model in Section 3, where the bridge damping factor was set to $c_{2}=3.42 \times 10^{4} \mathrm{Ns} / \mathrm{m}$, which corresponded to a first-order damping ratio of $1 \%$. The authors of this study assumed that the average vehicle mass was $m_{v}=1000 \mathrm{~kg}$, the average vehicle stiffness was $k_{v}=5.070 \times 10^{5} \mathrm{~N} / \mathrm{m}$, and the average damping factor was $c_{v}=3.82 \times 10^{3} \mathrm{Ns} / \mathrm{m}$. The VBI system frequencies and damping ratios for different number of vehicles were then calculated. The known conditions were the number of vehicles $n$, and the vehicle mass $m_{v}$, as well as the frequency $\omega$ and damping ratios $\xi$ of the VBI system.

The average vehicle stiffness $k_{v}$ was estimated using a PSO algorithm with the parameters set as follows: the number of populations was 30 , the number of iterations was 30 , and the range of particles was $1 \times 10^{5} \sim 1 \times 10^{6} \mathrm{~N} / \mathrm{m}$, which corresponded to the vehicle self-oscillation frequency range of $1.6 \sim 5 \mathrm{~Hz}$.

The optimization value of the objective function is shown in Figure 9. By the 30th iteration, the objective function values of all particles were less than $0.5 \times 10^{-3}$, so the global optimum had converged. The final estimate of the average vehicle stiffness was $5.072 \times 10^{5} \mathrm{~N} / \mathrm{m}$, which indicated that this algorithm could accurately estimate the equivalent vehicle stiffness. The estimated equivalent vehicle stiffness was used to calculate the bridge frequency, and the results are shown in Figure 10. The calculated bridge frequency was very close to the actual value and did not change with the number of vehicles.

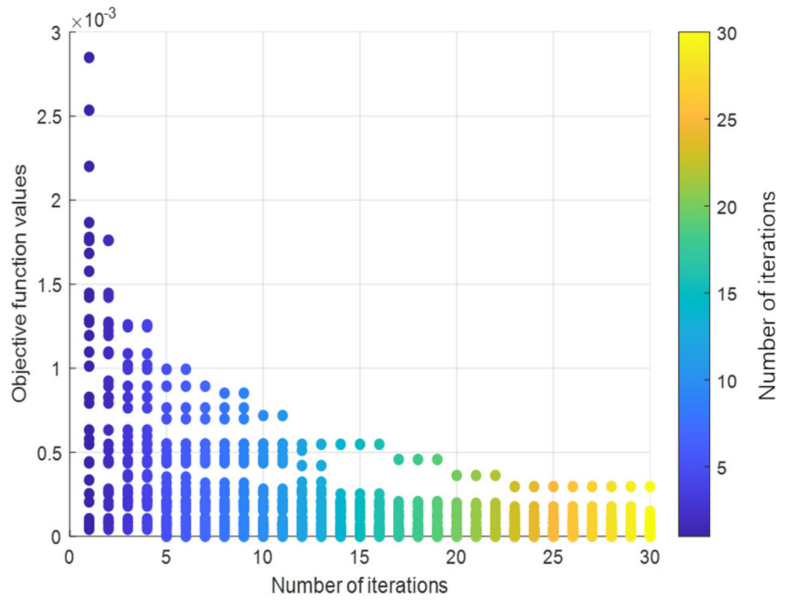

Figure 9. The objective function value of each particle.

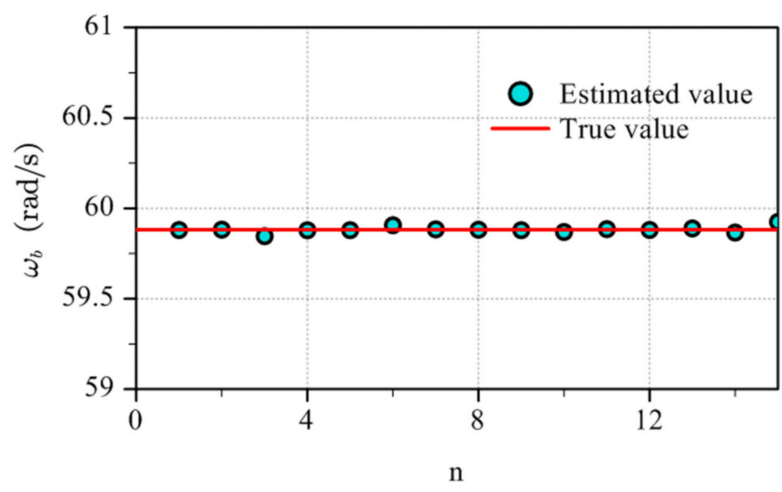

Figure 10. Estimation of bridge frequency under different number of vehicles.

After obtaining the equivalent vehicle stiffness estimate of $k^{\prime}$, the ratio of bridge vibration to vehicle vibration amplitude $t$ could be calculated according to Equation (10). The curve of the identified values of the bridge damping coefficient $c_{2}$ for different number 
of vehicles was plotted by substituting a series of trial values of $c$ in Equation (24). Here, the range of the average vehicle damping coefficient was $0 \sim 4.5 \times 10^{4}$, corresponding to the vehicle damping ratio of $0 \sim 1$. The vertical coordinate corresponding to the intersection point of the curve was the identification value of the bridge damping coefficient.

Figure 11 shows the bridge damping coefficient identification curve in relation to different numbers of vehicles. The curves corresponding to different numbers of vehicles intersect at one point. The intersection point corresponds to the horizontal coordinate of $3.82 \times 10^{3}$, and the vertical coordinate of the intersection point is $3.42 \times 10^{4}$, indicating that the average vehicle damping coefficient and bridge damping coefficient could be accurately estimated by this method.

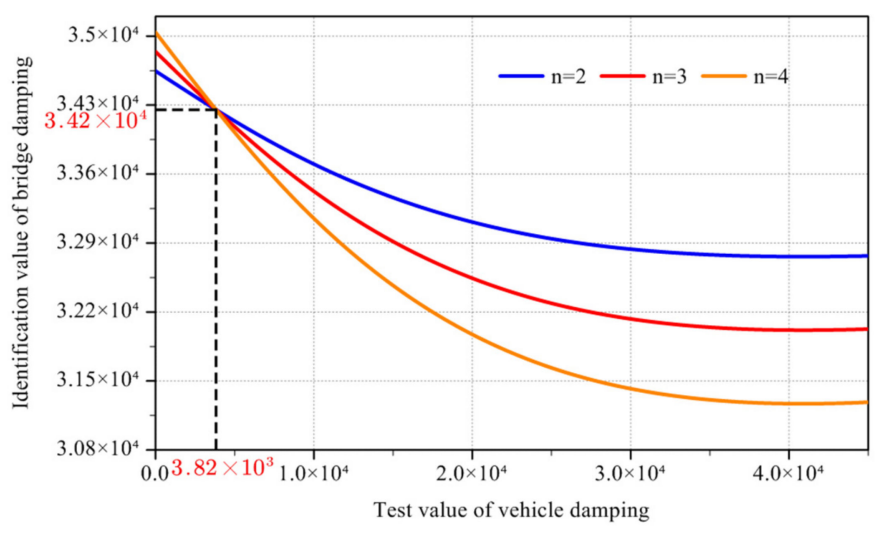

Figure 11. Identification curves of bridge damping coefficients.

\section{Application}

In this section, a single-tower cable-stayed bridge with a span of $336 \mathrm{~m}$ is used as a case study to assess damping, as shown in Figure 12. The bridge was equipped with a bridge health monitoring system that monitored the structural response, environment, and vehicle loads. Using the bridge mid-span acceleration data, the damping ratio of the vehicle-bridge system was calculated, and the information about the vehicles on the bridge was obtained through the WIM system. The damping ratio of this bridge was then extracted using the method proposed in this paper.

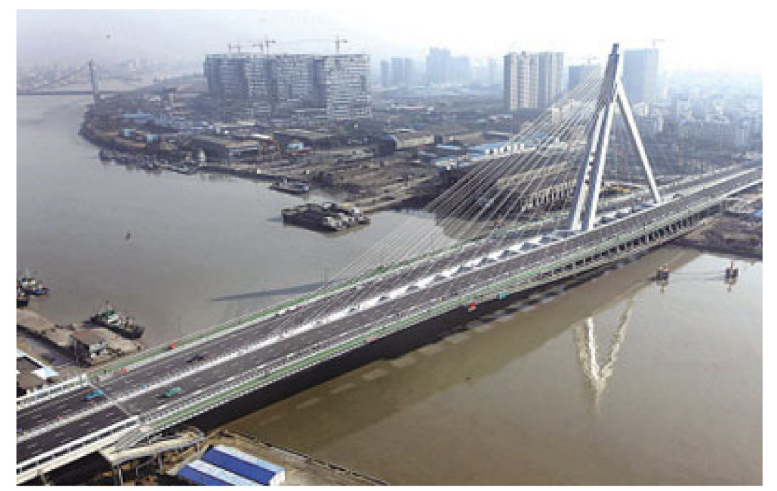

Figure 12. The case bridge.

\subsection{Simplified Model of the Bridge}

To analyze the cable-stayed bridge using the simplified VBI model proposed in this paper, the bridge needed to be simplified, and the elastic foundation beam model could be used to simplify the cable-stayed bridge by making the following assumptions:

1. The stiffened beam was simplified to a uniform Euler beam with the same boundary conditions as the real bridge. 
2. The tension cables were simplified to vertical springs distributed continuously along the length of the stiffened beam.

3. The axial force of the stiffened beam was uniformly distributed in the beam.

The governing differential equation for the simplified bridge can be written as:

$$
E I \frac{\partial^{4} u}{\partial x^{4}}+m \frac{\partial^{2} u}{\partial t^{2}}+P \frac{\partial^{2} u}{\partial x^{2}}+K_{w} u=0
$$

where $P$ is the axial force of the stiffener beam and $K_{w}$ is the equivalent spring stiffness.

The case bridge was modeled with the parameters $E I=3.75 \times 10^{11} \mathrm{Nm}^{2}$, $m=2.25 \times 10^{4} \mathrm{~kg} / \mathrm{m}, K_{w}=3 \times 10^{5} \mathrm{~N} / \mathrm{m}$, and $P=3 \times 10^{7} \mathrm{~N}$. The obtained vertical self-oscillation frequencies of the first three orders were basically consistent with the measured results, as shown in Table 2.

Table 2. First three order frequency of the bridge.

\begin{tabular}{ccc}
\hline Order & Calculated Value (Hz) & Measured Value (Hz) \\
\hline 1 & 0.59 & 0.55 \\
2 & 0.78 & 0.86 \\
3 & 1.23 & 1.31 \\
\hline
\end{tabular}

Using Equation (25), the double-beam system could be constructed according to the method in Section 2 to obtain the damping ratio calculation equation for the simplified axle coupling system. The expression of the formula is in the same form as Equation (17), and the specific derivation process can be found in [35]. After obtaining the simplified damping ratio formula for the axle system, the damping ratio of the bridge could be extracted by combining the measured data according to the method in Section 4.

\subsection{Bridge Damping Ratio Evaluation}

Figure 13 shows the mid-span acceleration data from 12:00 to 12:59 on a certain day, with a sampling frequency of $50 \mathrm{~Hz}$. The data were band-pass filtered to identify the first order frequency and damping ratio. In the filtered data, the free decay response was selected as the sample for damping identification, as shown in Figure 14. The selfoscillation frequency and damping ratio were calculated using the HHT method. The identification results are shown in Table 3. From the table, it can be seen that when the number of vehicles on the bridge increased, the identification self-oscillation frequency decreased and the damping ratio increased. The identified damping ratio ranged from $0.83 \%$ to $1.19 \%$, showing a large dispersion.

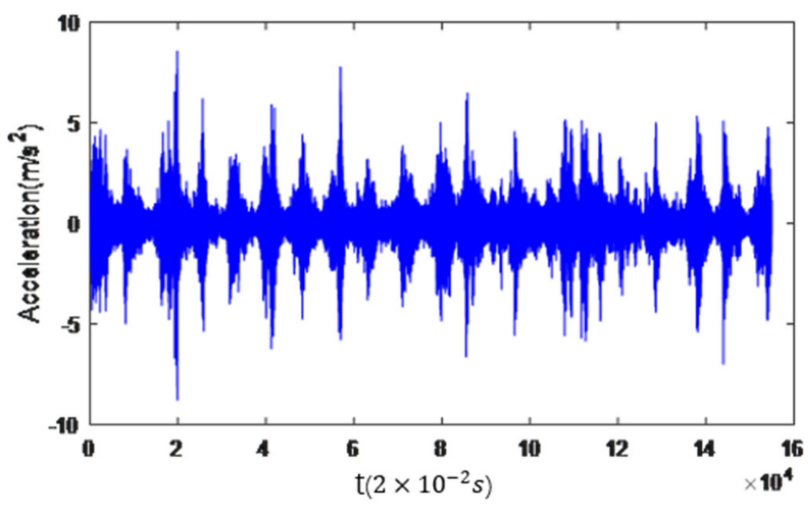

Figure 13. Mid-span acceleration data from 12:00 to 12:59. 


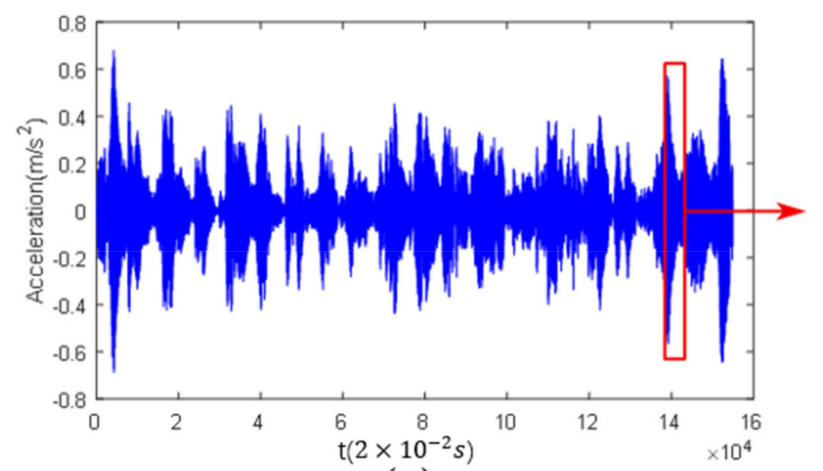

(a)

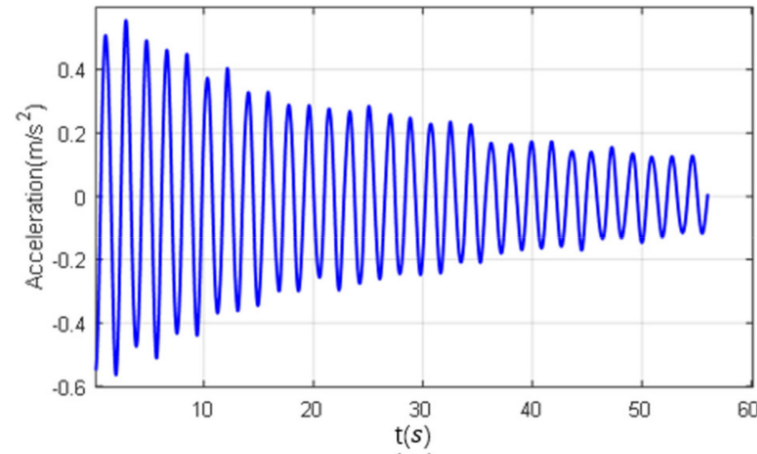

(b)

Figure 14. (a) Acceleration after band-pass filteringl (b) extracted decay response.

Table 3. Modal parameter identification results.

\begin{tabular}{ccccc}
\hline Sample & Frequency (Hz) & Damping Ratio (\%) & $\begin{array}{c}\text { Number of Vehicles on the } \\
\text { Bridge }\end{array}$ & $\begin{array}{c}\text { Total Mass of Vehicle on } \\
\text { Bridge (kg) }\end{array}$ \\
\hline 1 & 0.5402 & 0.85 & 5 & 6153 \\
2 & 0.5413 & 0.83 & 1 & 2520 \\
3 & 0.5343 & 1.19 & 20 & 26,515 \\
4 & 0.5421 & 0.9 & 15 & 17,288 \\
5 & 0.5426 & 0.87 & 6 & 8278 \\
\hline
\end{tabular}

We considered the results of the table obtained from the monitoring data (In Figure 14) as the frequency and damping ratio of the VBI system, and we analyzed these data using the bridge damping ratio evaluation method proposed in Section 4 . The equivalent traffic flow stiffness was first estimated using the PSO algorithm. The result was $8.15 \times 10^{3}$, and the convergence of each particle is shown in Figure 15.

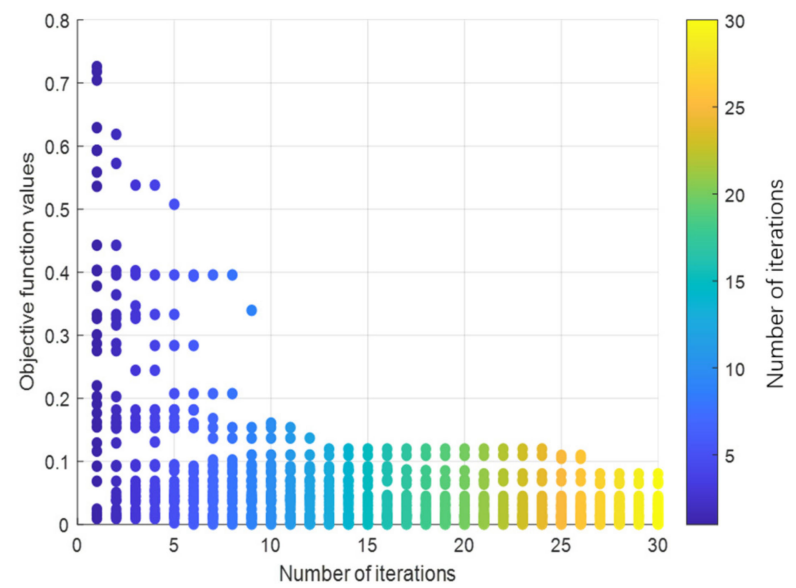

Figure 15. The objective function value of each particle.

The identification curve of the bridge damping coefficient was obtained as shown in Figure 16. The damping coefficient identification curves of the bridge did not intersect completely at one point, and the range of the intersection point was between 1260 and 1315, corresponding to the first-order damping ratio of the bridge of $0.75 \%-0.78 \%$. It can be seen that after extracting the bridge damping using the proposed method, the obtained bridge damping dispersion was significantly reduced. The reason for this phenomenon was that 
the traffic load was random traffic flow under operating conditions, which was not strictly consistent with the assumptions of the simplified VBI model proposed in this paper.

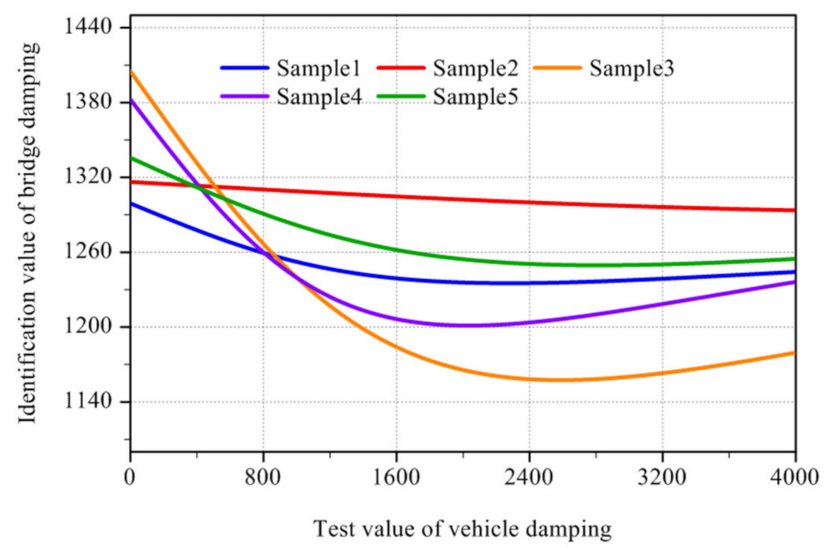

Figure 16. Bridge damping identification curve (12:00 12:59).

Sample 2 was calculated with only one vehicle on the bridge, and the damping ratio was $0.83 \%$. We approximated that $0.83 \%$ was the real damping ratio of the bridge. It can be seen that the bridge damping identification values of $0.75 \sim 0.78 \%$ were close to the real values. The above analysis proves that the method proposed in this paper is still valid in engineering applications and can remove the influence of the vehicle-bridge coupling effect on bridge damping evaluation.

To illustrate the stability of the algorithm proposed in this paper, the acceleration data from 13:00 to 13:59 on the same day were selected. The traffic load at this time had some similarity with that from above, so the equivalent vehicle stiffness obtained earlier was directly used here for identification. The identification results are shown in Figure 17. The intersection range was $1368 \sim 1380$, corresponding to a bridge damping ratio of $0.81 \sim 0.82 \%$, and the results were basically consistent with the previous results.

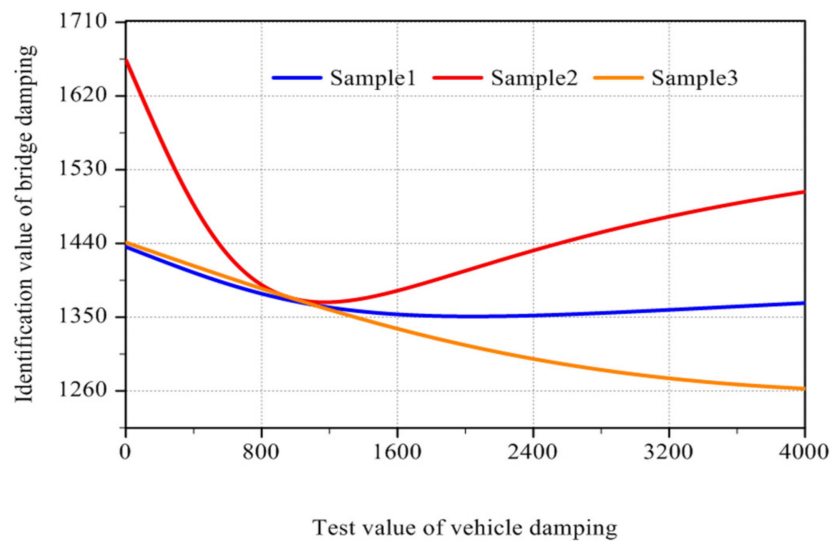

Figure 17. Bridge damping identification curve (13:00 13:59).

\section{Conclusions}

The authors of this paper examined bridge damping evaluation in relation to VBI systems. The damping ratio calculation method was obtained by simplifying a VBI system into a double-beam system and then solving the simplified model using the extended dynamic stiffness method. The main results are as follows:

1. Numerical tests showed that the damping ratios of the double-beam finite element model and the VBI model were basically consistent with the values calculated with the simplified model. In other words, the simplified method proposed in this paper can accurately calculate the damping ratio of a VBI system. 
2. The numerical simulation results showed that the equivalent traffic flow stiffness obtained using the proposed PSO estimation method $\left(5.072 \times 10^{5} \mathrm{~N} / \mathrm{m}\right)$ was very close to the real value $\left(5.070 \times 10^{5} \mathrm{~N} / \mathrm{m}\right)$. The feasibility of the proposed method was verified by plotting the bridge damping identification curves for different number of vehicles and obtaining the damping estimates of the bridge and the equivalent traffic flow from the intersection of the curves.

3. The damping ratios obtained using the proposed method were less discrete compared to those directly obtained using monitoring data. These results indicated that the proposed method can be applied to practical engineering projects to extract bridge damping values, eliminate the influence of the vehicle-bridge coupling effect on bridge damping identification, and reduce the dispersion of damping identification.

Author Contributions: Conceptualization, F.H. and Y.X.; methodology, F.G.; software, F.G.; validation, F.H., Y.W., and Y.X.; formal analysis, F.G.; investigation, F.G.; resources, Y.X.; data curation, F.G.; writing-original draft preparation, F.G.; writing-review and editing, F.H. and Y.W; visualization, F.G.; supervision, Y.X.; project administration, Y.X.; funding acquisition, Y.X. All authors have read and agreed to the published version of the manuscript.

Funding: This paper was supported by the National Key R\&D Program of China (2019YFB1600702), Transportation Science and Technology Program of Shandong Province (2021B51), National Natural Science Foundation of China (51978508), and Technology Cooperation Project of Shanghai Qizhi Institute (SYXF0120020109).

Institutional Review Board Statement: Not applicable.

Informed Consent Statement: Not applicable.

Data Availability Statement: Data are contained within the article.

Acknowledgments: We would like to acknowledge the reviewers who provided constructive suggestions that helped us improve our work. We also acknowledge Danhui Dan from Tongji University for his suggestions for this paper.

Conflicts of Interest: The authors declare no conflict of interest.

\section{References}

1. Zhu, X.Q.; Law, S.S. Structural health monitoring based on vehicle-bridge interaction: Accomplishments and challenges. Adv. Struct. Eng. 2015, 18, 1999-2015. [CrossRef]

2. Farrar, C.R.; Doebling, S.W.; Cornwell, P.J.; Straser, E.G. Variability of modal parameters measured on the Alamosa Canyon Bridge. In Proceedings of the 1997 15th International Modal Analysis Conference, IMAC. Part 2 (of 2), Orlando, FL, USA, 3-6 February 1997; pp. 257-263.

3. Xia, Y.; Lei, X.; Wang, P.; Liu, G.; Sun, L. Long-term performance monitoring and assessment of concrete beam bridges using neutral axis indicator. Struct. Control Health Monit. 2021, 27, e2637. [CrossRef]

4. Kim, C.-Y.; Jung, D.-S.; Kim, N.-S.; Kwon, S.-D.; Feng, M.Q. Effect of vehicle weight on natural frequencies of bridges measured from traffic-induced vibration. Earthq. Eng. Eng. Vib. 2003, 2, 109-115. [CrossRef]

5. Yang, Y.B.; Cheng, M.C.; Chang, K.C. Frequency Variation in Vehicle-bridge Interaction Systems. Int. J. Struct. Stab. Dyn. 2013, 13, 1350019. [CrossRef]

6. Li, J.; Zhu, X.; Law, S.-S.; Samali, B. Time-varying characteristics of bridges under the passage of vehicles using synchroextracting transform. Mech. Syst. Signal Process. 2020, 140, 106727. [CrossRef]

7. Matsuoka, K.; Kaito, K.; Sogabe, M. Bayesian time-frequency analysis of the vehicle-bridge dynamic interaction effect on simple-supported resonant railway bridges. Mech. Syst. Signal Process. 2020, 135, 106373. [CrossRef]

8. Cantero, D.; Hester, D.; Brownjohn, J. Evolution of bridge frequencies and modes of vibration during truck passage. Eng. Struct. 2017, 152, 452-464. [CrossRef]

9. Hwang, D.; Kim, S.; Kim, H.-K. Long-Term Damping Characteristics of Twin Cable-Stayed Bridge under Environmental and Operational Variations. J. Bridge Eng. 2021, 26. [CrossRef]

10. Rebelo, C.; Simoes da Silva, L.; Rigueiro, C.; Pircher, M. Dynamic behaviour of twin single-span ballasted railway viaducts-Field measurements and modal identification. Eng. Struct. 2008, 30, 2460-2469. [CrossRef]

11. Sunjoong, K.; Kwang-Yeun, P.; Ho-Kyung, K.; Hae Sung, L. Damping estimates from reconstructed displacement for lowfrequency dominant structures. Mech. Syst. Signal Process. 2020, 136, 106533. [CrossRef] 
12. Wang, H.; Mao, J.X.; Huang, J.H.; Li, A.Q. Modal identification of sutong cable-stayed bridge during typhoon haikui using wavelet transform method. J. Perform. Constr. Facil. 2016, 30, 04016001. [CrossRef]

13. Sunjoong, K.; Ho-Kyung, K. Damping identification of bridges under nonstationary ambient vibration. Engineering 2017, 3 , 839-844. [CrossRef]

14. Dan, D.; Yu, X.; Han, F.; Xu, B. Research on dynamic behavior and traffic management decision-making of suspension bridge after vortex-induced vibration event. Struct. Health Monit. 2021. [CrossRef]

15. Yang, Y.B.; Lin, C.W.; Yau, J.D. Extracting bridge frequencies from the dynamic response of a passing vehicle. J. Sound Vib. 2004, 272, 471-493. [CrossRef]

16. Bu, J.Q.; Law, S.S.; Zhu, X.Q. Innovative bridge condition assessment from dynamic response of a passing vehicle. J. Eng. Mech 2006, 132, 1372-1379. [CrossRef]

17. Kim, C.-W.; Kawatani, M. Pseudo-static approach for damage identification of bridges based on coupling vibration with a moving vehicle. In Advances in Reliability and Optimization of Structural Systems; Taylor and Francis Ltd.: Abingdon-on-Thames, UK, 2008.

18. Siringoringo, D.M.; Fujino, Y. Estimating bridge fundamental frequency from vibration response of instrumented passing vehicle: Analytical and experimental study. Adv. Struct. Eng. 2012, 15, 417-433. [CrossRef]

19. Jian X., D.; Xia, Y.; Sun L, M. An indirect method for bridge mode shapes identification based on wavelet analysis. Struct. Control Health Monit. 2020, 27, e2630. [CrossRef]

20. Han, F.; Dan, D.; Cheng, W. Extension of dynamic stiffness method to complicated damped structures. Comput. Struct. 2018, 208, 143-150. [CrossRef]

21. Fei, H.; Danhui, D.; Wei, C.; Jubao, Z. A novel analysis method for damping characteristic of a type of double-beam systems with viscoelastic layer. Appl. Math. Model. 2020, 80, 911-928. [CrossRef]

22. Wittrick, W.H.; Williams, F.W. A general algorithm for computing natural frequencies of elastic structures. Q. J. Mech. Appl. Math. 1971, 24, 263-284. [CrossRef]

23. Han, F.; Dan, D.; Cheng, W.; Jubao, Z. An improved Wittrick-Williams algorithm for beam-type structures. Compos. Struct. 2018, 204, 560-566. [CrossRef]

24. Han, F.; Dan, D.; Cheng, W. An exact solution for dynamic analysis of a complex double-beam system. Compos. Struct. 2018, 193, 295-305. [CrossRef]

25. Yuan, S.; Ye, K.; Williams, F.W. Second order mode-finding method in dynamic stiffness matrix methods. J. Sound Vib. 2004, 269, 689-708. [CrossRef]

26. Yuan, S.; Ye, K.; Williams, F.W.; Kennedy, D. Recursive second order convergence method for natural frequencies and modes when using dynamic stiffness matrices. Int. J. Numer. Methods Eng. 2003, 56, 1795-1814. [CrossRef]

27. Zhang, N.; Xia, H. Dynamic analysis of coupled vehicle-bridge system based on inter-system iteration method. Comput. Struct. 2013, 114-115, 26-34. [CrossRef]

28. Yang, J.N.; Lei, Y.; Pan, S.; Huang, N. System identification of linear structures based on Hilbert-Huang spectral analysis. Part 1 : Normal modes. Earthq. Eng. Struct. Dyn. 2003, 32, 1443-1467. [CrossRef]

29. Magalhaes, F.; Cunha, A. Explaining operational modal analysis with data from an arch bridge. Mech. Syst. Signal Process. 2011, 25, 1431-1450. [CrossRef]

30. Pioldi, F.; Ferrari, R.; Rizzi, E. Output-only modal dynamic identification of frames by a refined FDD algorithm at seismic input and high damping. Mech. Syst. Signal Process. 2016, 68-69, 265-291. [CrossRef]

31. Brownjohn, J.M.W.; Siu-Kui, A.; Yichen, Z.; Zhen, S.; Binbin, L.; Bassitt, J.; Hudson, E.; Hongbin, S. Bayesian operational modal analysis of Jiangyin Yangtze River Bridge. Mech. Syst. Signal Process. 2018, 110, 210-230. [CrossRef]

32. Bagley, J.D. The Behavior of Adaptive Systems Which Employ Genetic and Correlation Algorithms; ProQuest LLC: Ann Arbor, MI, USA, 1967.

33. Holland, J.H. Genetic algorithms and the optimal allocation of trials. SIAM J. Comput. 1973, 2, 88-105. [CrossRef]

34. Kennedy, J.; Eberhart, R. Particle swarm optimization. In Proceedings of the 1995 IEEE International Conference on Neural Networks. Part 1 (of 6), Perth, Australia, 27 November-1 December 1995; pp. 1942-1948.

35. Han, F.; Dan, D.; Cheng, W. Exact dynamic characteristic analysis of a double-beam system interconnected by a viscoelastic layer. Compos. Part B Eng. 2019, 163, 272-281. [CrossRef] 